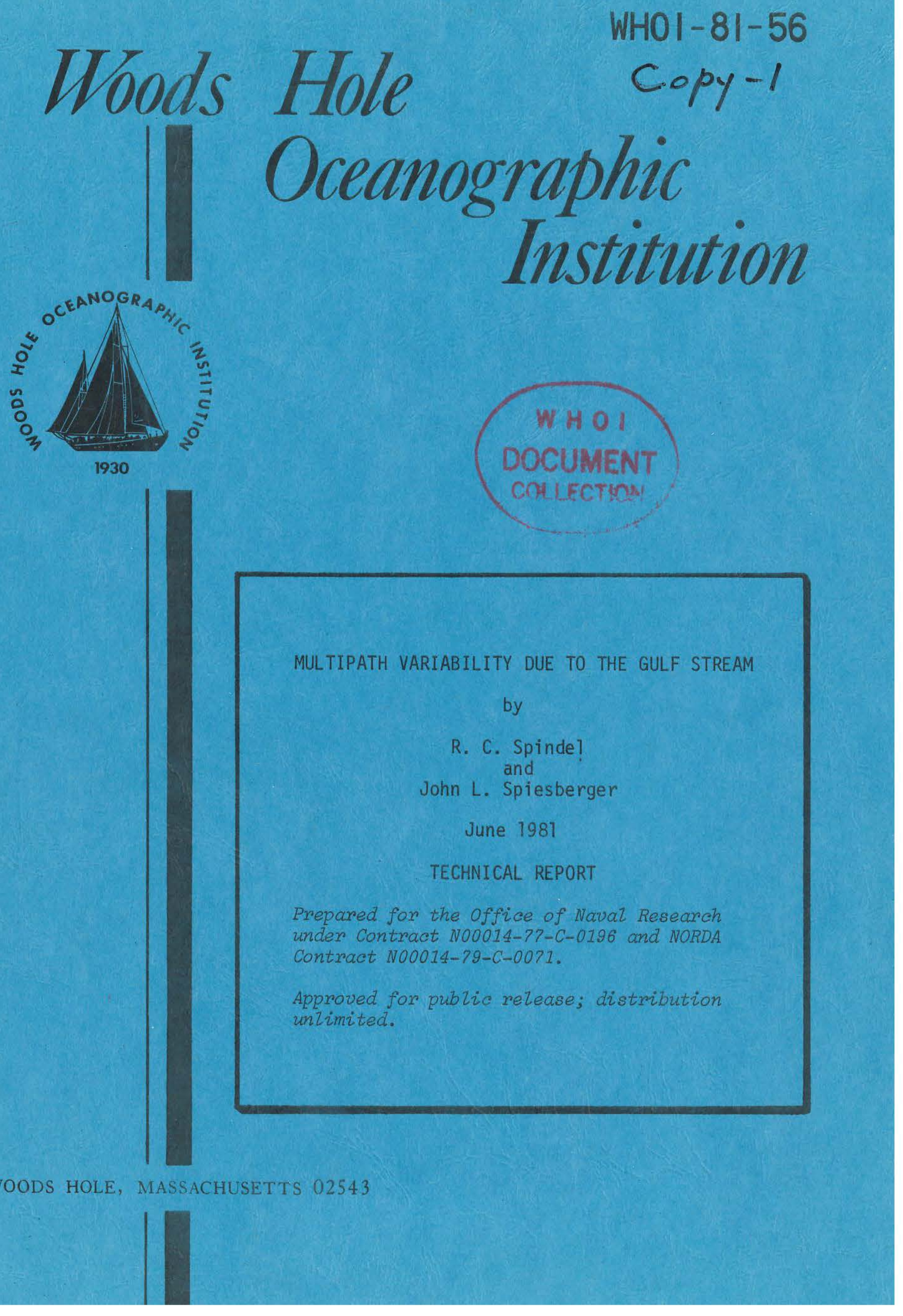


WHOI-81-56

\title{
MULTIPATH VARIABILITY DUE TO THE GULF STREAM
}

by

\author{
R. C. Spindel \\ and \\ John L. Spiesberger \\ WOODS HOLE OCEANOGRAPHIC INSTITUTION \\ Woods Hole, Massachusetts 02543
}

June 1981

TECHNICAL REPORT

Frepared for the Office of Naval Research under Contract N00014-77-C-0196 and NORDA Contract N00014-79-C-0071.

Reproduction in whole or in part is permitted for any purpose of the United States Goverment. In citing this report in a bibliography, the reference given should be to: J.Acoust. Soc. Am. 69(4): 982-988 (April 1981).

Approved for public release; distribution unlimited.

Approved for Distribution: Earl E. Hays, Chairman

Department of Ocean Engineering 


\title{
Multipath variability due to the Gulf Stream
}

\author{
R. C. Spindel \\ Department of Ocean Engineering, Woods Hole Oceanographic Institution, Woods Hole, Massachusetts 02543
}

\section{John L. Spiesberger}

Scripps Institution of Oceanography, University of California, San Diego, La Jolla, California 92093

(Received 9 June 1980; accepted for publication 12 November 1980)

\begin{abstract}
A phase-coded signal with $64-\mathrm{ms}$ resolution was transmitted at 10-min intervals for a 19-day period over two $\sim 300-\mathrm{km}$ ranges. The acoustic source was moored at 2000-m depth northwest of Bermuda. One receiver was moored at 2000-m depth to the northeast of the source and the other receiver was bottom mounted at $\sim 1000$ $\mathrm{m}$ depth near Bermuda. The large ( $\sim 0.6 \mathrm{~s})$ travel time change at the Bermuda receiver is probably due in large part to motion of the source mooring in the presence of currents. The multipath arrival pattern at the moored receiver undergoes significant modification due to the presence of a southern meander of the Gulf Stream which intersects this transmission path.
\end{abstract}

PACS numbers: $43.30 . \mathrm{Bp}$

\section{INTRODUCTION}

In a 1978 experiment, Spiesberger et al ${ }^{1}$ resolved long range $(\sim 900 \mathrm{~km})$ acoustic multipaths for a 48 -day period. Absolute variations in travel time were not measured, but relative variations between multipaths ranged from 0 to $50 \mathrm{~ms}$. The resolution and stability of the multipaths and the precision of the measurement of multipath arrival times were adequate for measuring ocean mesoscale variability by a method called "ocean acoustic tomography. " The experiment was part of an ongoing study to measure ocean mesoscale structure using long range pulsed acoustic transmissions.

In this paper we describe a second experiment conducted for 19 days in April-May 1979 in which variations in absolute travel time were measured. An acoustic source was tautly (1000-lb tension) moored $\sim 300$ $\mathrm{km}$ to the northwest of Bermuda at 2-km depth. An acoustic receiver was moored $313 \mathrm{~km}$ to the northeast of the source also at $2-\mathrm{km}$ depth. The top of each single point mooring was well below the surface (source 750 $\mathrm{m}$, receiver $1000 \mathrm{~m}$ ) to minimize mooring motion. An additional bottom-mounted receiver was located near Bermuda at $\sim 1-\mathrm{km}$ depth at $\sim 300-\mathrm{km}$ range (Fig. 1 ). This experiment was an engineering test of prototype instruments intended for use in future ocean monitoring experiments. As a result, mooring motions were not measured and only a few environmental measurements were made. Regardless of these shortcomings, some sense can be made of the interesting records at the two receivers. Observed travel time variations are related principally to a southern meander of the Gulf Stream and to mooring motions. We present data from this experiment to show the variability of multipaths which propagate through the Gulf Stream.

\section{ACOUSTIC SIGNAL AND SIGNAL PROCESSING}

In several recent papers we have discussed a selfcontained, portable system that allows the direct measurement of acoustic travel time variations along individual multipaths at long ranges. ${ }^{3,4}$ Signals with large time-bandwidth product are transmitted and processed upon reception by either phase-only or phase and amplitude matched filtering. The signal is designed to have a sharp autocovariance peak so that the pulse-compressed reception can be interpreted as an arrival from an equivalent transmitted pulse.

A $220-\mathrm{Hz}$ carrier frequency is phase modulated by a 4-s long, 63-digit pseudorandom sequence. Each digit of the modulating code is approximately $64 \mathrm{~ms}$. In the case of phase-only matched filtering or "sharp-processing" the covariance peak is $64 \mathrm{~ms}$ wide. ${ }^{1}$ The more

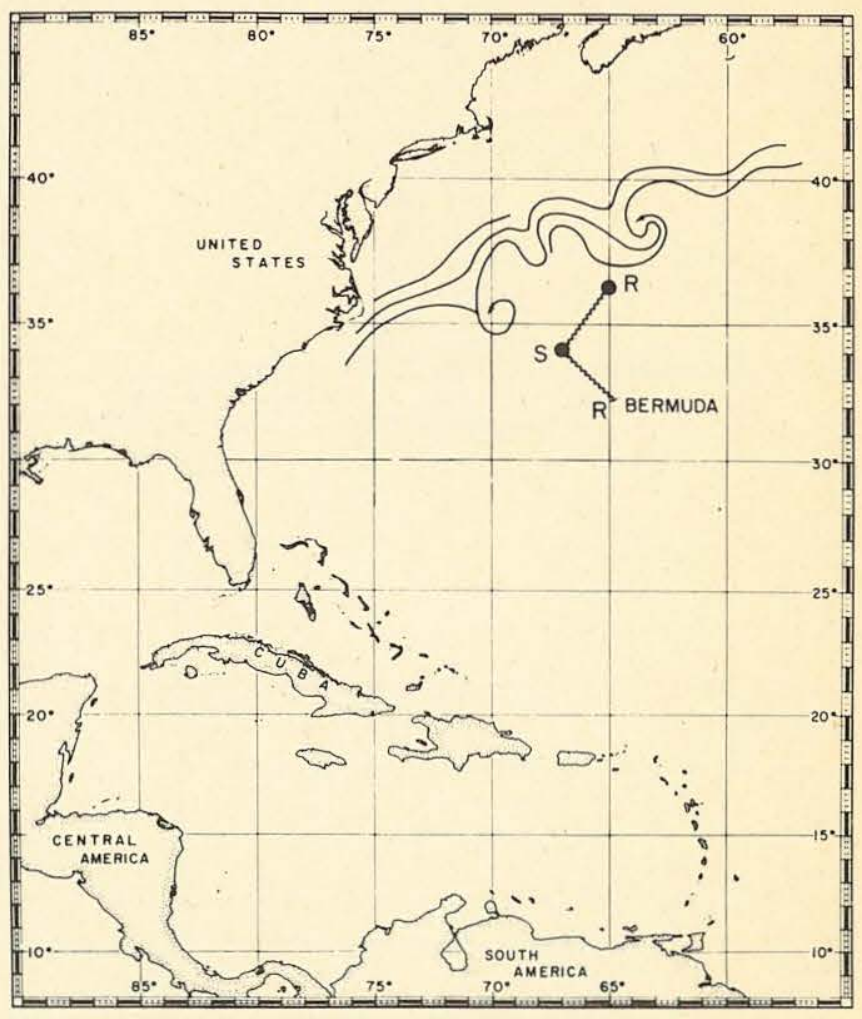

FIG. 1. The moored source $(S)$ located at $34^{\circ} 06^{\prime} \mathrm{N}, 67^{\circ} 07^{\prime} \mathrm{W}$ transmits to two receivers $(R)$. The moored receiver is at $36^{\circ}$ $21^{\prime} \mathrm{N}, 65^{\circ} 01^{\prime} \mathrm{W}$ and the fixed receiver is near Bermuda. The moored receiver is in the proximity of a southern meander of the Gulf Stream. 
conventional phase and amplitude matched filtering results in a covariance peak with greater signal-to-noise ratio at the expense of decreased resolution which is $127 \mathrm{~ms}$ (Fig. 2). Both types of processing were used. Sixteen consecutive sequences of the 4 -s signal were transmitted at $10-$ min intervals.

Signal processing at the fixed Bermuda receiver is described in detail in Ref. 1. Essentially, it consists of coherently averaging consecutive sequences (to increase the signal-to-noise ratio) followed by sharp processing. At the moored receiver, the signal processing scheme is almost identical except that the sampling frequency is one-quarter that at Bermuda. This reduction results in slightly degraded resolution which is seen clearly in Fig. 3, where we show typical records from both the Bermuda and moored receivers.

Since the objective of future experiments is to measure travel time variations of the multipath field due to changes in the structure of the ocean sound speed field, time keeping errors in the acoustic source or receivers must be small compared with time changes caused by ocean variability. Such errors will result in apparent travel time changes which are indistinguishable from those due to ocean processes. Hence both source and receivers are equipped with high stability clocks. The moored receiver clock was stable to within a few parts in $10^{9}$ /day; the Bermuda receiver and moored source contained rubidium clocks stable to within a few parts in $10^{11} /$ month. Measured clock errors at Bermuda, the
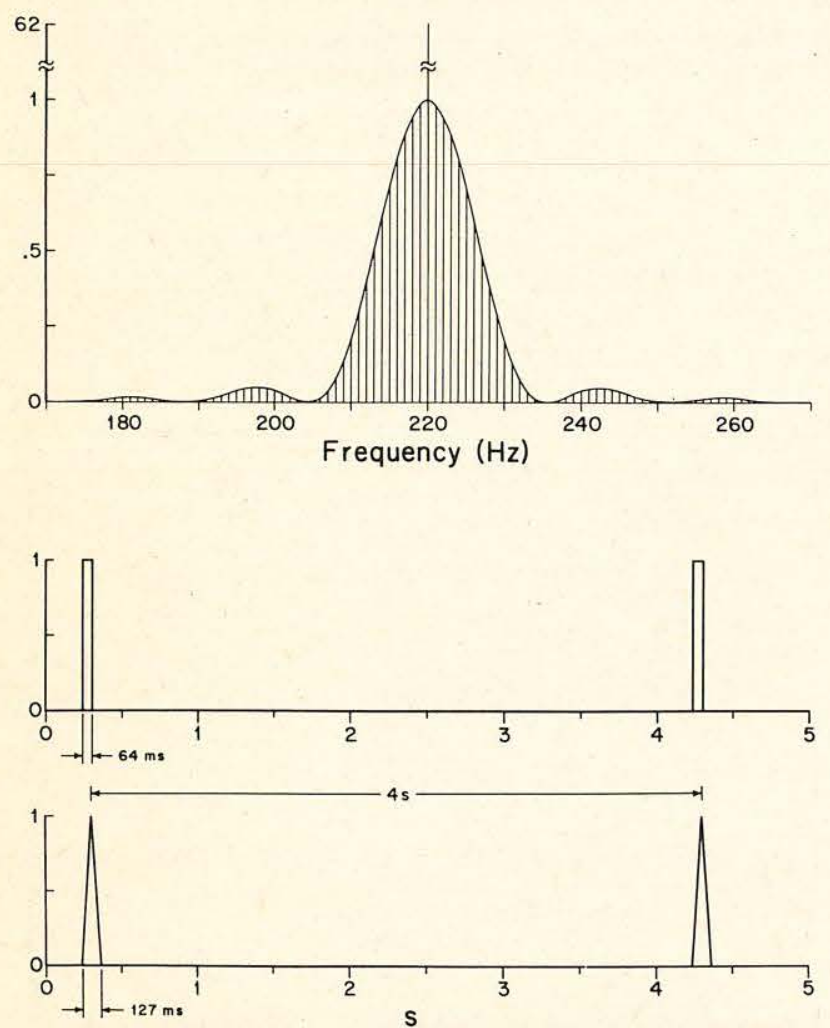

FIG. 2. Top: The ideal transmitted power spectrum consists of lines at $0.25-\mathrm{Hz}$ spacing, only one-quarter of which are shown. Middle: The ideal normalized"sharp-processed" filter output for two consecutive sequences along a single multipath. Bottom: The ideal normalized matched filter output.
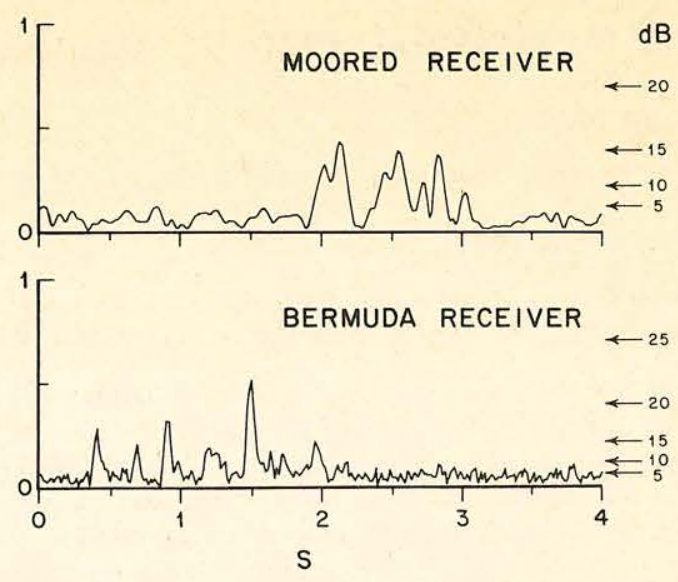

FIG. 3. Typical "sharp-processed" amplitude records. Arrival times are relative. Many multipaths stand above the background noise level. Signal-to-noise ratios are indicated on the right.

moored receiver and the moored source were less than $10 \mu \mathrm{s}, 5 \mathrm{~ms}$, and $100 \mu \mathrm{s}$, respectively.

\section{OBSERVED MULTIPATHS}

The multipaths are recorded at 10-min intervals except for one 4-h gap at the Bermuda receiver. There are typically 5-8 prominent arrivals per record (Fig. 3).

We have plotted the arrival time of all peaks from the matched filtered records whose signal-to-noise ratios exceed $10 \mathrm{~dB}$ at the moored receiver and $7 \mathrm{~dB}$ at the Bermuda receiver (Fig. 4). The position of each peak
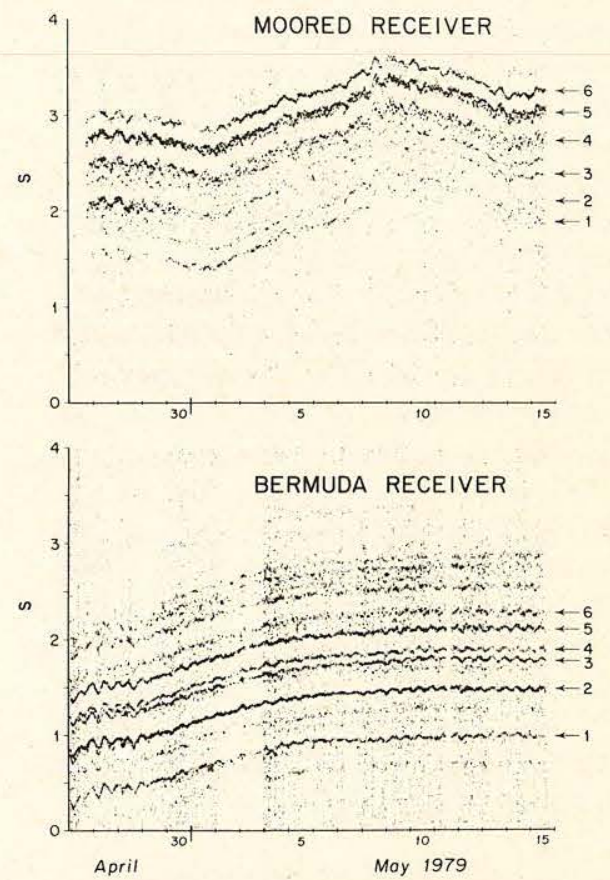

FIG. 4. Travel time variations (reckoned from an arbitrary zero) of multipaths are recorded at 10-min intervals over a 19-day period. Only peaks having signal-to-noise ratios exceeding $10 \mathrm{~dB}$ (upper panel) and $7 \mathrm{~dB}$ (lower panel) are allowed, with dot size proportional to this ratio. Prominent arrivals are labeled for later reference. 

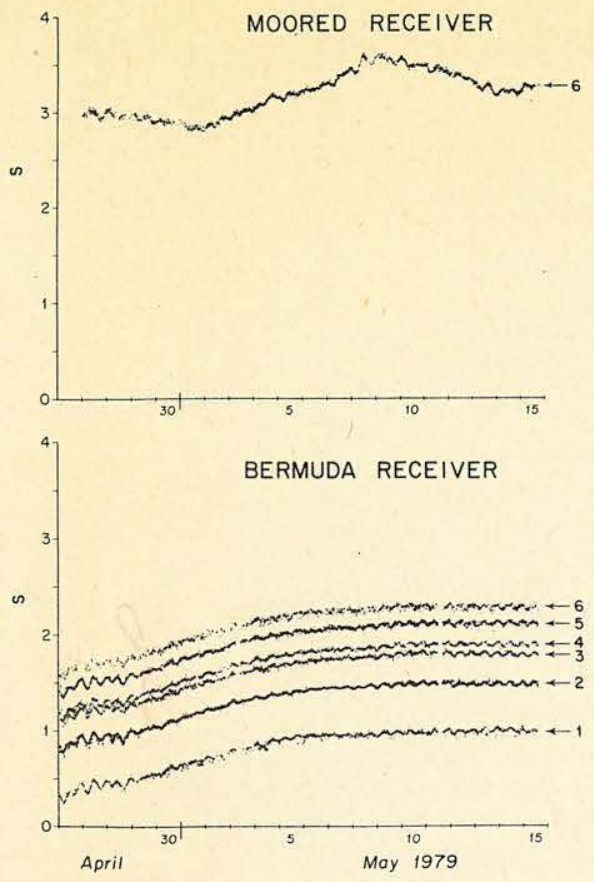

FIG. 5. The tracked time series for various arrivals. Labels (right) are the same as Fig. 4.

is marked by a dot whose size is proportional to the peak signal-to-noise ratio. The average peak signalto-noise ratio is 15 to $20 \mathrm{~dB}$. Prominent arrivals from this plot are extracted by centering them in time windows of fixed width and selecting the largest enclosed peak (Fig. 5). Only one arrival (\#6) from the moored receiver was tracked due to difficulties in tracking the other arrivals.

The travel times at the moored receiver decrease by $\sim 160 \mathrm{~ms}$ between 27 April-1 May, increase by $\sim 690 \mathrm{~ms}$ between 1-8 May, decrease by $\sim 300 \mathrm{~ms}$ between $8-14$ May, then increase by $\sim 25 \mathrm{~ms}$ between 14-16 May. The amplitudes of early arriving multipaths fluctuate more than the amplitudes of the later arriving multipaths. Late arrivals leave the source at shallow angles and do not cycle into the highly variable upper portion of the water column, whereas early arrivals have upper turning points near $500-\mathrm{m}$ depth.

The travel times at the Bermuda receiver increase by

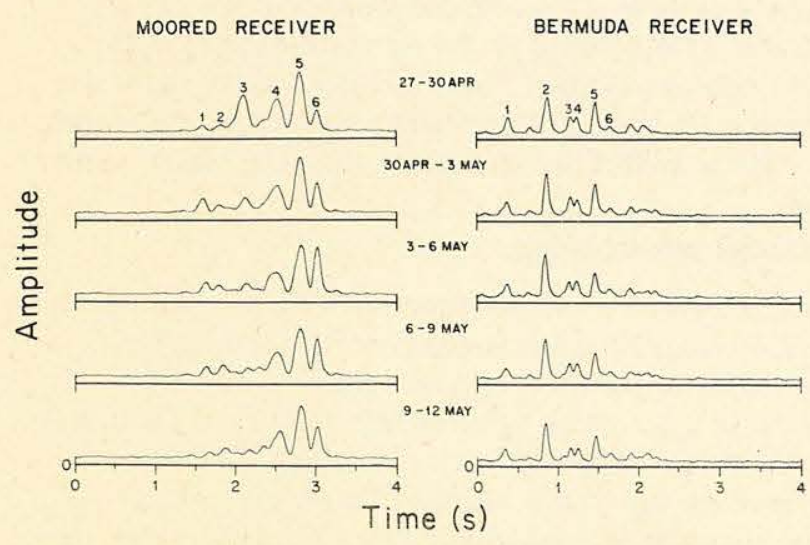

FIG. 6. Consecutive 3-day incoherent averages.

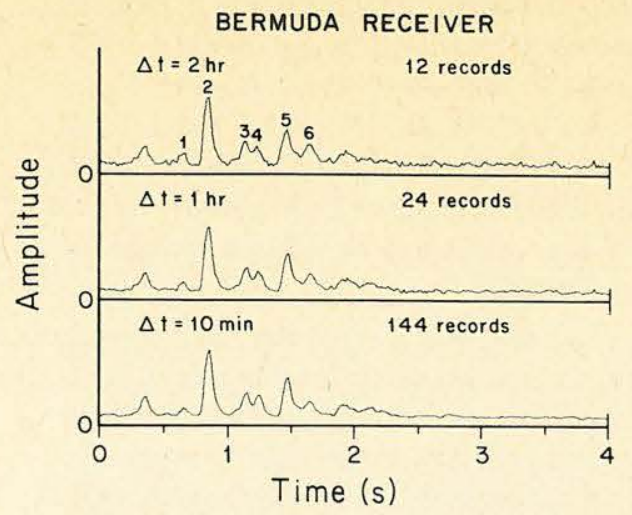

FIG. 7. The averages for 6 May using 12 records at $2-\mathrm{h}$ intervals, 24 records at 1 - $h$ intervals, and 144 records at 10-min intervals at the Bermuda receiver.

$590 \mathrm{~ms}$ between 26 April-6 May. The travel time changes little from 6 May until the experiment conclusion. In striking contrast to the moored receiver records, the average amplitudes of these multipaths are nearly constant throughout the experiment.

\section{INCOHERENT AVERAGING}

To measure average multipath structure we reduce 10 - min variability by forming averages of intensities (amplitudes squared) from consecutive sharp-processed records. The previous experiment indicated that averages exceeding one-half day greatly reduce variability. ${ }^{1}$ To prevent smearing of the multipaths, most of the high-frequency ( $>2$ cycles/day) travel time fluctuations are removed prior to summation. This is

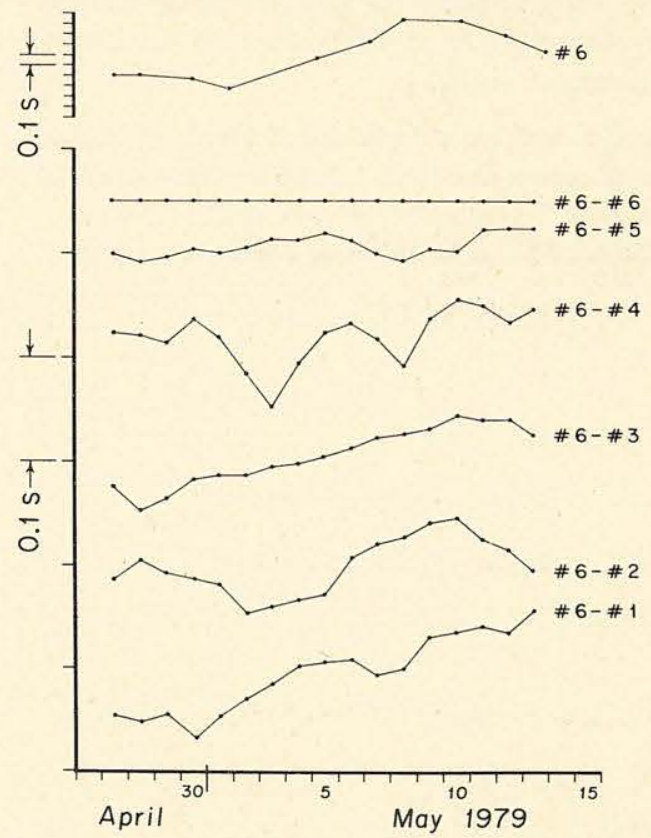

FIG. 8. Top: Travel time variations of arrival \#6 (upper panel Fig. 5) at the moored receiver. Full scale represents $1 \mathrm{~s}$ of travel time change. Bottom: Travel time differences on an amplified scale between individual paths and the reference path $\# 6$ at the moored receiver. The vertical positioning of the curves is arbitrary except that arrival order is maintained. 
achieved by choosing path \# 6 from the moored receiver and path \# 5 from the Bermuda receiver (Fig. 5) as time origins. The standard deviations of arrival time above 2 cycles/day for the reference paths are $\sim 14 \mathrm{~ms}$. One then expects less than 14-ms smearing in the incoherent average which is small compared with the $64-\mathrm{ms}$ pulse width. Details of the incoherent averaging method have been described previously. ${ }^{1}$

Figure 6 shows consecutive 3 -day (432 records) averages (we average intensities and plot the square root). At the moored receiver, the amplitudes of arrivals \# 3 and \# 6 change much more than arrivals \# 1 , $\# 2$, \#4, and \#5. Consecutive 3-day averages at the Bermuda receiver exhibit little variability.

Figure 7 shows three different daily averages at the Bermuda receiver on 6 May. We have plotted this data to determine an approximate minimum sampling frequency to accomplish ocean monitoring through acoustic multipath measurements. We find that averages of 12 records at 2 -h separation or 24 records at 1 -h separation match the 3-day averages of Fig. 6 quite well. Note that in both Figs. 6 and 7 the time origin has been shifted so that the gross travel time changes in Fig. 4 are not evident.

\section{ARRIVAL TIME FLUCTUATIONS}

It has been suggested that changes in the sound speed profile can be inferred from travel time perturbations of resolved multipaths. Indeed, this notion is central to the implementation of acoustic tomography as described by Munk and Wunsch. ${ }^{2}$ Multipaths with shallow upper turning points (steep rays) sample the upper ocean whereas flat rays sample the ocean near the sound channel axis. In Figs. 8 and 9 we plot arrival time differences between multipaths to illustrate the magnitude of variation for various rays.

For the moored receiver we choose arrival \#6 (upper panel Fig. 5) as a reference path. It is the last arrival and corresponds to a relatively flat ray that is more stable than those which cycle into the variable, upper

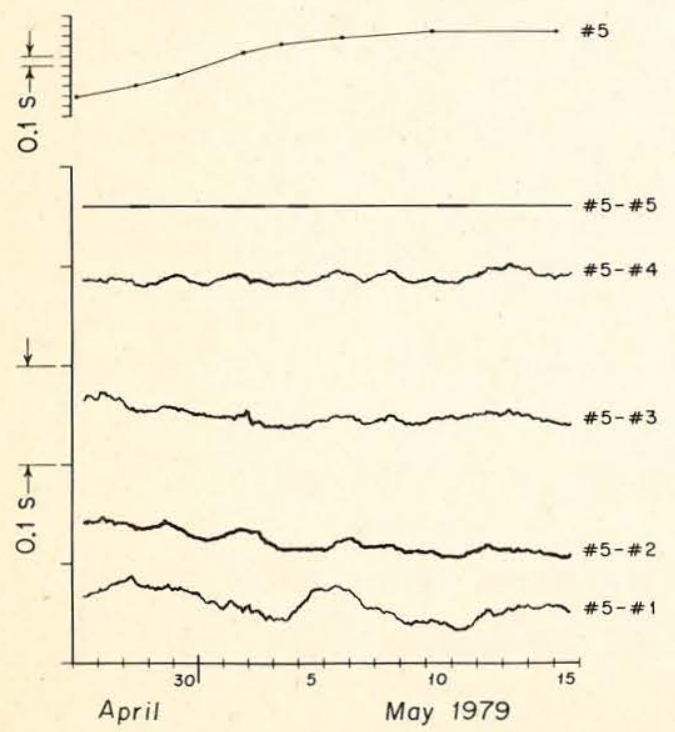

FIG. 9. Same as Fig. 8. except at the Bermuda receiver.

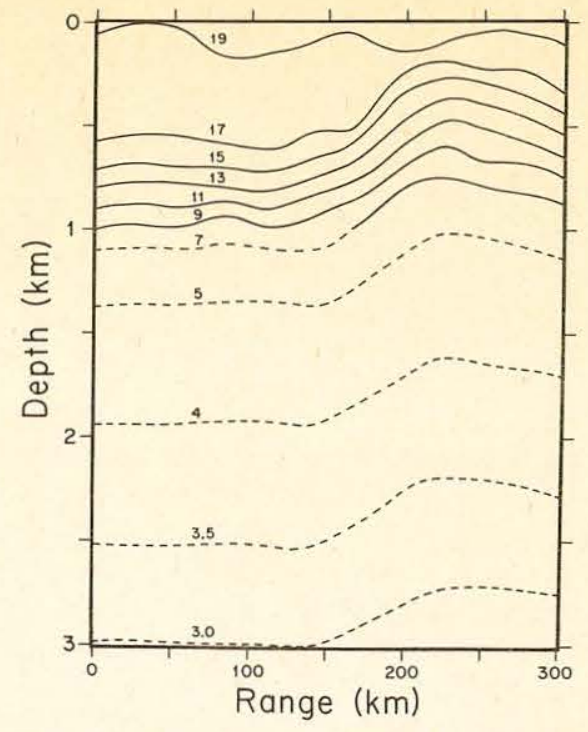

FIG. 10. Measured (solid) and extrapolated (dashed) isotherms between the moored source (left) and moored receiver (right) on 26 April 1979. Temperature was measured from ten $1800-\mathrm{m}$ XBT's and a bottle cast.

part of the water column. Arrival time differences between this reference and five other arrivals are measured from seventeen consecutive day-length incoherent averages (Fig. 8). Arrival time differences vary by approximately $100 \mathrm{~ms}$ over the 19-day experiment. With the exception of the \#6-\#4 pair, the earliest arrivals appear to fluctuate the greatest amount. This is in keeping with the notion that early arrivals sample the variable upper ocean. Figure 3 , which is not averaged, and Fig. 4 both indicate that some of the average multipath arrivals (\#3, \#4, and \#5 of Fig. 6) actually consist of partially resolved paths and that these paths are separated in arrival time by the approximate resolution limit of the system (order 100 $\mathrm{ms})$. This is especially true of arrival \#4. We believe that some of the variability in the \#6-\#4 path difference is due to alternating domination of the average by two partially resolved paths.

In the case of the Bermuda receiver, arrival \# 5 (lower panel Fig. 5) is chosen as the reference. Arrival times on the tracked peak plot (Fig. 5) are subtracted from the reference. Running daily averages are formed and plotted in Fig. 9. Travel time differences of up to $40 \mathrm{~ms}$ occur during the 19-day experiment. Note that it is the earliest arrival ( $\# 1$ ) whose relative arrival time fluctuates by the greatest amount ( $40 \mathrm{~ms})$. This path has a shallow upper turning point and samples the relatively variable upper ocean.

\section{MOORING MOTION}

Strong currents can produce mooring excursions that result in travel time changes due to shortening or lengthening of the transmission path. A horizontal excursion of $1 \mathrm{~km}$ (with an attendant downward excursion of $\sim 150 \mathrm{~m}$ ) is required to give rise to a $0.6-\mathrm{s}$ travel time change due to the leaning of a single mooring. Using geometrical optics ray tracing, we find that the multipath arrival pattern is only slightly sensitive to an 
excursion of this magnitude. Total travel times change by the required $0.6 \mathrm{~s}$, but travel time differences change by less than $20 \mathrm{~ms}$ and amplitudes change by less than $2 \mathrm{~dB}$.

In the case of the Bermuda receiver observed arrival time differences ranged from 0 to $40 \mathrm{~ms}$ and amplitudes remained nearly constant (Fig. 6). Thus it is possible to account for most of the observed variability by assuming a gradual $1-\mathrm{km}$ leaning of the source mooring over a 10-day period although a static model of the mooring requires a rather large current to achieve such displacement. A current decreasing from 2.5 $\mathrm{m} / \mathrm{s}$ at the surface to $0.5 \mathrm{~m} / \mathrm{s}$ at $1000-\mathrm{m}$ depth and then linearly to $0.1 \mathrm{~m} / \mathrm{s}$ at the bottom $(5 \mathrm{~km})$, which is representative of a strong Gulf Stream profile, results in a $1-\mathrm{km}$ horizontal excursion. ${ }^{5,6}$ The only evidence for the existence of a current of this magnitude near the source mooring is the anomalously large travel time fluctuation at tidal frequencies at the beginning of the record in Fig. $4 .^{7}$ We conclude that most of the observed variability at the Bermuda receiver could be the result of mooring motion.

In contrast, the observed $\sim 100-\mathrm{ms}$ travel time differences and $\sim 10-\mathrm{dB}$ amplitude fluctuations at the moored receiver are too great to be caused by a $1-\mathrm{km}$ mooring excursion. We conclude that most of the travel time variability in this case is a result of changes in the ocean along this transmission path.

\section{OCEANOGRAPHIC OBSERVATIONS AND DISCUSSION}

In Fig. 10 we have plotted isotherms from XBT probes dropped every $27 \mathrm{~km}$ between source and receiver at the commencement of the experiment. Dotted lines are hypothesized isotherms based on historical observations of the deep structure of cold Gulf Stream rings and meanders. A hydrographic station to $5-\mathrm{km}$ depth at the location of the source on 24 April provided additional data for this figure (courtesy V. Worthington). Approximately $40 \%$ of the path is dominated by a large cold water mass which, interestingly, is not evident from observation of near surface temperature alone. Hence it is not surprising that an infrared TIROS N satellite image of the area (Fig. 11) does not indicate the presence of this cold water mass. In Fig. 12 we show sound speed profiles based on XBT and hydrographic data. There is a marked decrease in sound speed as one progresses from source to receiver; maximum variation is $25 \mathrm{~m} / \mathrm{s}$ at $800-\mathrm{m}$ depth.

In Fig. 13 we have plotted the approximate position of the south wall of the Gulf Stream deduced from satellite images and available bathythermograph data by the Experimental Frontal Analysis Group of the Naval Oceanographic Office. Also in Fig. 13 we have plotted a more detailed set of contours based on an aircraft XBT survey executed on 21 May showing that the portion of the Gulf Stream near the acoustic path is actually a large southern meander. Numbered line positions and the dates on which they occur are imprecise due to poor visual contrast in the satellite photographs, cloud cover, and obvious near surface temperature uniformity

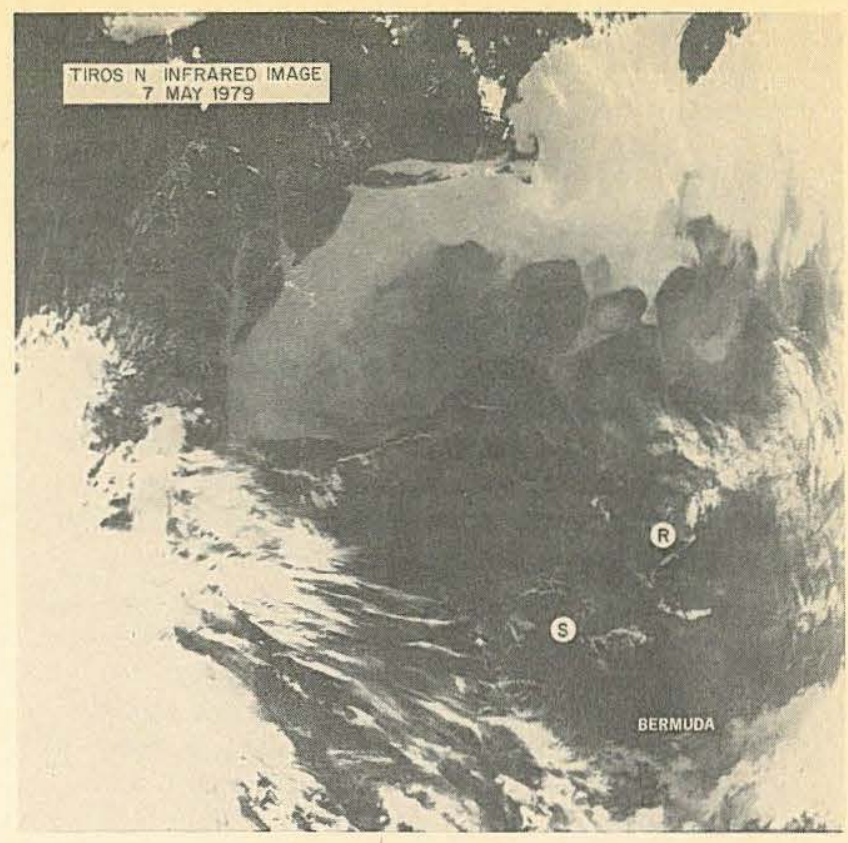

FIG. 11. Sea surface termperature is indicated by white for cold and black for warm water.

(Fig. 10). However, the general sequence of northsouth meander drift is roughly correct and, within about a week, corresponds to the acoustic data. This one week discrepancy is within the accuracy of Gulf Stream frontal position based on satellite images. The meander appears to have moved slightly north moving cold water out of the path, then moved south to cover most if not all of the path with cold water, and finally to have retreated from the path altogether. Further evidence for an infusion of cold water is provided by the temperature record of Fig. 14 derived from a thermistor mounted in the moored receiver. From 27

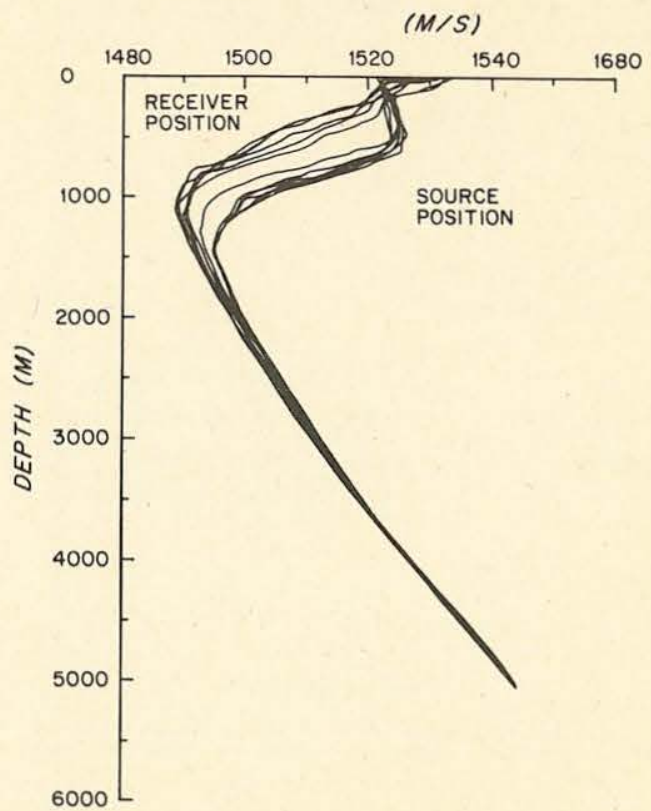

FIG. 12. Sound speed profiles calculated from XBT's and historical data between source and moored receiver on 26 April 1979. 
April to 2 or 3 May there is a gradual rise in temperature, a drop of about $0.1^{\circ} \mathrm{C}$ follows until 9 May and then the temperature rises again until 15 May.

An estimate of the overall travel time change to be expected from the influx of cold water is obtained by simple geometric optics ray trace theory. If the path consisted only of water represented by the sound speed profile at the source on 26 April (that is, no cold water present) the computed travel time for the most axial ray path is $209.4 \mathrm{~s}$. If the path consisted entirely of water represented by the profile taken at the receiver on 26 April, the travel time of the most axial ray is 209.9 s. The net change in arrival time between these extreme cases is $0.5 \mathrm{~s}$. The data of Fig. 4 shows a difference of $0.69 \mathrm{~s}$ from 26 April to 9 May. These most axial rays cycle to within about $1000 \mathrm{~m}$ of the surface. The steepest nonsurface reflected rays have upper turning points at about 500-m depth. A similar calculation for these rays yields a travel time difference of $0.8 \mathrm{~s}$ for the two extreme cases. They cycle through the upper part of the water column where the sound speed changes are greater than for near axis rays. These rough calculations show that the presence or absence of the Gulf Stream meander can give rise to most of the observed 0.69 -s travel time changes.

Without mooring motion data and much more initial environmental data, it is unlikely that ocean structure can be inferred from inverse theory. Instead we try to reconcile observations with two oversimplified models. Both models assume that travel time changes at the moored receiver are primarily due to temperature fluc-

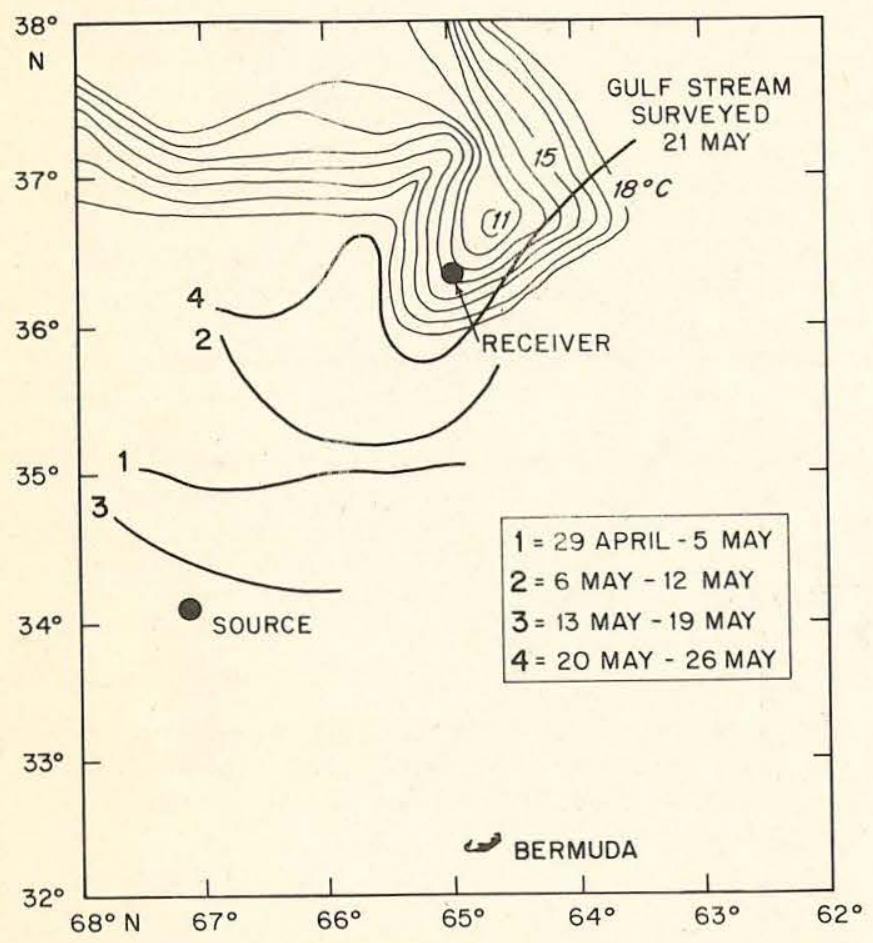

FIG. 13. Approximate positions of the south wall of the Gulf Stream are numbered 1-4. Surface contours of temperature near the moored receiver were computed from an AXBT survey.

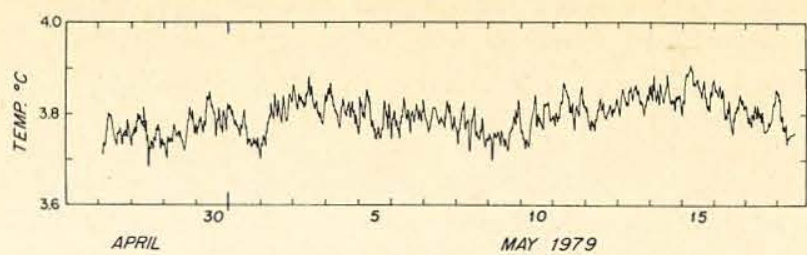

FIG. 14. Temperature measurements at the moored receiver (at $2-\mathrm{km}$ depth).

tuations. Current effects are secondary except insofar as they force mooring motions which can be considerable. ${ }^{7}$ For example, the travel time change, $\Delta t$, due to a barotropic current $u=1 \mathrm{~m} \cdot \mathrm{s}^{-1}$ over a range $R$ $=300 \mathrm{~km}$ is $\Delta t=R u / c^{2}=0.13 \mathrm{~s}$ where $c=1.5 \mathrm{~km} \mathrm{~s}^{-1}$. This exaggerated estimate is considerably less than the $\sim 0.7-\mathrm{s}$ travel time change due to temperature considerations alone.

One can crudely model travel time fluctuations by supposing that the fractional amount of slope water (water north of the Gulf Stream) along the transmission path (Fig. 13) is linearly related to travel time change at the moored receiver. Take $\Delta t_{\text {slope }}=0.5 f \mathrm{~s}$, where $f$ is the fraction of slope water along the path. The linear relationship is chosen to that a $0.5-\mathrm{s}$ travel time change results from $f$ taking the extreme values 0 and 1 as in the ray trace example above. $\Delta t_{\text {slope }}$ lags the acoustic observations by about one week and is about one-half the amplitude (Fig. 15). The correspondence is not unreasonable considering the very rough locations of the Gulf Stream front given by Fig. 13.

Another (but not necessarily correct) model can be constructed by assuming a linear relationship between travel time changes and measured temperatures at the moored receiver. The fractional change in sound speed is related to changes in temperature through

$$
\Delta C / C \approx 3 \times 10^{-3} \Delta \theta .
$$

Consider a two layer ocean where the temperature anomaly above $1.5-\mathrm{km}$ depth is $M \Delta \theta$, where $\Delta \theta$ is the observed lowpassed temperature fluctuation measured at $2-\mathrm{km}$ depth at the moored receiver. $M$ is an empirical magnification factor relating temperature fluctuations at $2-\mathrm{km}$ depth to average fluctuations above $1.5-$

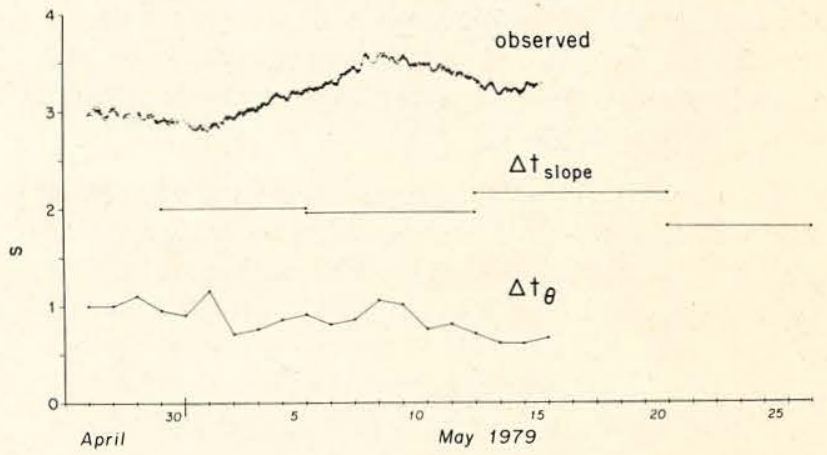

FIG. 15. Observed and inferred variations of travel time at the moored receiver. $\Delta t_{\text {slope }}$ in the inferred fluctuation due to the fraction of slope water along the path and $\Delta t_{\theta}$ in the inferred fluctuation from temperature measurements at the moored receiver. 
$\mathrm{km}$ depth. The order of magnitude of observed temperature fluctuations above $1.5-\mathrm{km}$ depth are $\sim 2-3^{\circ} \mathrm{C}$ due to the presence or absence of slope water. These are a factor of $M \sim 25$ greater than the $0.1^{\circ} \mathrm{C}$ temperature fluctuations at $2-\mathrm{km}$ depth. Then a travel time anomaly of about

$$
\Delta t_{\theta} \approx-(\Delta C / C)(D / C) M=-5 \Delta \theta
$$

seconds occurs due to a $\Delta \theta^{\circ} \mathrm{C}$ temperature change at the moored receiver where $D=100 \mathrm{~km}$ is the approximate distance a ray spends in the upper layer over a $300-\mathrm{km}$ range. Daily lowpassed values of $\Delta \theta$ from Fig. 14 are used to calculate $\Delta t_{\theta}$ (Fig. 15). With the exception of one point on $1 \mathrm{May}, \Delta t_{\theta}$ somewhat resembles the acoustic observations.

Neither model is able to distinguish between travel time fluctuations due to large scale temperature fluctuations or those due to mooring motions. For example, the fractional amount of slope water between source and moored receiver might be related to large currents and these in turn might result in large mooring displacements. Similarly, temperature fluctuations measured at the receiver are related to changing water temperature as well as vertical mooring excursions. However, at least in the case of the moored receiver, the preponderance of evidence points to acoustic travel time variations that are due primarily to movement of a Gulf Stream meander and consequent infusion of cold slope water along the transmission path, and only partly due to mooring motion.

\section{CONCLUSIONS}

The variability of the amplitudes ( $\sim 10-\mathrm{dB}$ changes) and arrival time differences ( $100 \mathrm{~ms})$ at the moored receiver are almost entirely due to the changing positions of the Gulf Stream meander with perhaps a small contribution from mooring motions. We are unable to determine the relative contribution of mooring motions to the observed 0.69 -s travel time change, but we believe that they are not the dominant causes. Observations of the position of the Gulf Stream meander are very approximate and, if adjusted by an acceptable one week shift, are in rough accord with the observed travel time changes. Additionally, travel time changes inferred from temperature measurements at the moored receiver are in rough agreement with observed travel time changes. We conclude that travel time variations are an important measure of large scale ocean dynamics and can be exploited in ocean monitoring schemes. We further conclude that when such schemes are implemented, mooring motions must be monitored.

In the case of the Bermuda receiver, the acoustic versus oceanographic interpretation is unclear. The 40- ms variability of travel time differences is only a factor of two greater than the (ray trace) prediction due to mooring motion. It is possible that sufficiently strong currents exist in the vicinity of the source mooring to produce the required horizontal excursion of $1 \mathrm{~km}$. Munk et al., ${ }^{7}$ offer arguments that allow mooring motion to account for most of the observed travel time change. We conclude in this case that mooring motion contributed a large amount to both the observed 590-ms travel time and to the $0-40 \mathrm{~ms}$ variability.

\section{ACKNOWLEDGMENTS}

The authors are indebted to the Acoustic Modeling Division of NORDA for their help with ray trace calculations with range-varying profiles and to the Naval Research Laboratory for providing ancillary XBT data. Valentine Worthington generously provided hydrographic data. John Clark generously provided much of the equipment used to collect data at Bermuda. Walter Munk made many useful suggestions in the preparation of this report. This research was supported under ONR Contract N00014-77-C-0196 and NORDA Contract N00014-79-C-0071. This is Contribution No. 4641 of the Woods Hole Oceanographic Institution.

${ }^{1}$ J. L. Spiesberger, R. C. Spindel, and K. Metzger, "Stability and identification of ocean acoustic multipaths," J. Acoust. Soc. Am. 67 (6), 2011-2017 (1980).

${ }^{2}$ W. Munk and C. Wunsch, "Ocean acoustic tomography: a scheme for large scale monitoring," Deep Sea Res. 26, 123-161 (1979).

${ }^{3}$ R. C. Spindel, K. R. Peal, and D. E. Koelsch, "A microprocessor acoustic data buoy," IEEE Oceans '78, 527-531 (1978).

${ }^{4}$ R. C. Spindel, "An underwater acoustic pulse compression system," IEEE Trans. Acoust. Speech Signal Proc. ASSP-27, 723-728 (1979).

${ }^{5}$ D. A. Moller, "A computer program for the design and static analysis of single-point subsurface mooring systems: NOYFB," Woods Hole Oceanographic Institution, WHOI 7659, June (1976).

${ }^{6} \mathrm{~J}$. Barrett and W. Schmitz, "Transport float measurements and hydrographic station data from three sections across the gulf stream near $67^{\circ} \mathrm{W}$," Woods Hole Oceanographic Institution, WHOI 71-66, November (1971).

${ }^{7}$ W. Munk, B. Zetler, J. Clark, S. Gill, D. Porter, J. Spiesberger, and R. Spindel, "Tidal effects on long-range sound transmission," submitted to J. Geophys. Res. (1980). 


\section{MANDATORY DISTRIBUTION LIST \\ FOR UNCLASSIFIED TECHNICAL REPORTS, REPRINTS, AND FINAL REPORTS PUBLISHED BY OCEANOGRAPHIC CONTRACTORS \\ OF THE OCEAN SCIENCE AND TECHNOLOGY DIVISION \\ OF THE OFFICE OF NAVAL RESEARCH}

(REVISED NOVEMBER 1978)

1 Deputy Under Secretary of Defense (Research and Advanced Technology) Military Assistant for Environmental Science Room 3D129

Washington, D.C. 20301

Office of Naval Research 800 North Quincy Street

Arlington, VA 22217

3 ATTN: Code 483

1 ATTN: Code 460

2 ATTN: 102B

1 CDR J. C. Harlett, (USN) ONR Representative Woods Hole Oceanographic Inst. Woods Hole, MA 02543

Commanding Officer Naval Research Laboratory Washington, D.C. 20375

6 ATTN: Library, Code 2627
12 Defense Documentation Center Cameron Station

Alexandria, VA 22314

ATTN: DCA

Commander

Naval Oceanographic Office NSTL Station

Bay St. Louis, MS 39522

1 ATTN: Code 8100

1 ATTN: Code 6000

1 ATTN: Code 3300

1 NODC/NOAA

Code D781

Wiscons in Avenue, N.W.

Washington, D.C. 20235 
SECURITY CLASSIFICATION OF THIS PAGE (When Date Ento:ed)

\begin{tabular}{|c|c|}
\hline REPORT DOCUMENTATION PAGE & $\begin{array}{l}\text { READ INSTRUCTIONS } \\
\text { BEFORE COMPLETING FORM }\end{array}$ \\
\hline $\begin{array}{l}\text { 1. REPORT NUMBER } \\
\text { WHOI-8I-56 }\end{array}$ & 3. RECIPIENT'S CATALOG NUMAER \\
\hline 4. TITLE (and Subtitlo) & 5. TYPE OF REPORT A PERIOO COVERED \\
\hline \multirow[t]{2}{*}{ MULTIPATH VARIABILITY DUE TO THE GULF STREAM } & Technical \\
\hline & $\begin{array}{l}\text { 6. PERFORMING ORG. REPORT NUMBER } \\
\text { WHOI Contr. } 4641\end{array}$ \\
\hline 7. AUTHOR(o) & 8. CONTRACT OR GRANT NUMBER(s) \\
\hline R.C. Spinde1 and John L. Spiesberger & $\begin{array}{l}\text { N00014-77-C-0196 } \\
\text { N00014-79-C-0071 }\end{array}$ \\
\hline 9. PERFORMING ORGANIZATION NAME AND ADDRESS & $\begin{array}{l}\text { 10. PROGRAM ELEMENT. PROJECT, TASK } \\
\text { AREAQWORK UNIT NUMERS. TSK }\end{array}$ \\
\hline $\begin{array}{l}\text { Woods Hole Oceanographic Institution } \\
\text { Woods Hole, Massachusetts } 02543\end{array}$ & \\
\hline \multirow{2}{*}{$\begin{array}{l}\text { 11. CONTROI LING OFFICE NAME AND ADDRESS } \\
\text { NORDA/National Space Technology Laboratory } \\
\text { Bay St. Louis, MS } 39529\end{array}$} & $\begin{array}{l}\text { 12. REPORT DATE } \\
\text { June } 1981 \\
\end{array}$ \\
\hline & 13. NUMBER OF PAGES \\
\hline 14. MONITORING AGENCY NAME \& ADDRESS(It diflerent from Controlline Offlco) & $\begin{array}{l}\text { 15. SECURITY CLASS. (of thla roport) } \\
\text { UnClaSSified } \\
\text { 15a. DECLSSSIFICATION/DOWNGRADING } \\
\text { SCHEDULE }\end{array}$ \\
\hline
\end{tabular}

17. DISTRIBUTION STATEMENT (of the abotract ontered in Block 20, if difforent trom Roport)

18. SUPPLEMENTARY NOTES

Reprinted from: J. Acoust. Soc. Am. 69(4): 982-988 (Apri1 1981).

19. KEY WOROS (Continue on reverve alde if neceesery and identify by block number)

1. Acoustic multipath

2. Acoustic signal processing

3. Acoustic fluctuations

20. ABSTRACT (Continue on roveree ofdo 1 neceeseary and identify by block number)

A phase-coded signal with 64 -ms resolution was transmitted at 10-min intervals for a 19-day period over two-300-km ranges. The acoustic source was moored at 2000-m depth northwest of Bermuda. One receiver was moored at 2000-m depth to the northeast of the source and the other receiver was bottom mounted at $\sim 1000-\mathrm{m}$ depth near Bermuda. The large $(\sim 0.6 \mathrm{~s})$ travel time change at the Bermuda receiver is probably due in large part to motion of the source mooring in the presence of currents. (cont. on next page) 
20.

The multipath arrival pattern at the moored receiver undergoes significant modification due to the presence of a southern meander of the Gulf Stream which intersects this transmission path. 


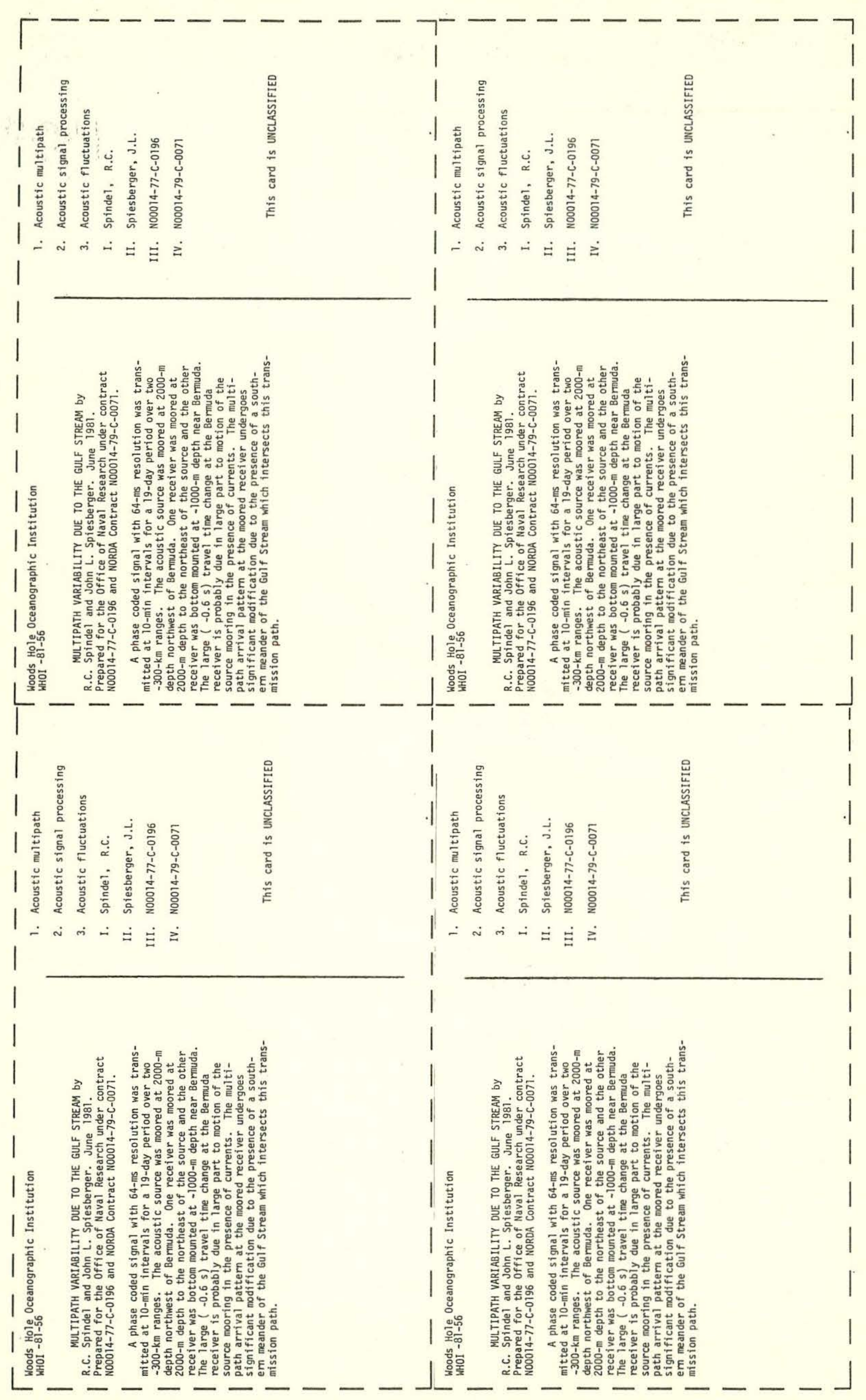

